\title{
LAS FUENTES PLAUTINAS DE LA COMEDIA HUMANÍSTICA LATINA “ANNULARIA” (ca. 1500), DE EGIDIO GALLO*
}

\author{
Antonio Arbea $G$. \\ Pontificia Universidad Católica de Chile \\ aarbea@uc.cl \\ María José Brañes G. \\ Pontificia Universidad Católica de Chile \\ mjbranes@uc.cl \\ Javier Beltrán H. \\ Pontificia Universidad Católica de Chile \\ jbeltra1@uc.cl
}

\section{RESUMEN / ABSTRACT}

Los estudiosos coinciden en señalar que los comediógrafos latinos -especialmente Plautofueron los modelos principales de la comedia humanística latina, a la que proporcionaron argumentos, esquemas, estructura y lengua. Está pendiente, sin embargo, establecer con exactitud y en detalle en qué medida esas fuentes antiguas determinaron el contenido y la forma de cada comedia humanística en particular. En este trabajo nos proponemos precisamente verificar la influencia léxica y fraseológica que ejerció Plauto sobre la comedia humanística latina Annularia (ca. 1500), de Egidio Gallo. Esta pieza, tras un examen detallado de su texto, aparece casi como un verdadero centón plautino.

Palabras Clave: centón, comedia humanística, latín, Renacimiento, Egidio Gallo, "Annularia”.

Este artículo es resultado del proyecto Fondecyt n ${ }^{\circ} 1100594$, titulado “Annularia, de Egidio Gallo (comedia humanística latina). Introducción, texto, traducción, notas e índice de palabras", en el que participan Antonio Arbea (investigador responsable), María José Brañes (doctoranda) y Javier Beltrán (ayudante). 
Scholars agree on saying that Latin playwrights -chiefly Plautus- set the benchmark for the Latin humanistic comedy, shaping its plots, schemes, structures and language. Nonetheless it remains to be established exactly how and to what extent these two sources from the past molded the content and the shape of every particular humanistic comedy. In this paper we intend to verify how Plautus lexically and phraseologically influenced the Latin $h^{1}$ umanistic comedy Annularia (ca. 1500) by Egidio Gallo. Surprisingly, after thorough examination, this play looks almost like a bona fide Plautine cento.

KEY WORDS: cento, humanistic comedy, Latin, Renaissance, Egidio Gallo, Annularia.

\section{INTRODUCCIÓN}

Dentro del conjunto de las así llamadas comedias humanísticas latinas -una cincuentena de piezas escritas casi todas durante el siglo XV italiano por jóvenes humanistas deseosos de imitar a Plauto y Terencio-, Annularia, de Egidio Gallo ${ }^{1}$, ocupa un lugar muy destacado. Esta pieza no solo es cronológicamente una de las últimas obras del género -se escribe hacia el 1500-, sino que en ella culmina el paulatino proceso de comprensión del carácter de la antigua comedia romana, a la que solo entonces, hacia el final del Quattrocento, tras intentos progresivamente más certeros, se llega a imitar con cierta destreza y conciencia.

No obstante este relieve histórico-literario de Annularia, ella no ha recibido aún la debida atención de los estudiosos. Hasta ahora, en efecto, la obra resulta prácticamente inaccesible, ya que solo se la puede leer en alguno de los tres ejemplares que se conservan de su primera y única edición de 1505, insuficiente en muchos aspectos ${ }^{2}$. Tampoco ha sido todavía traducida a ninguna lengua. El proyecto -aún en curso- en que se inscribe este artículo aspira a llenar ese vacío en los estudios filológicos latinos, ofreciendo la posibilidad

1 Como de gran parte de los autores de las comedias humanísticas, poco es lo que sabemos de Egidio Gallo. Por algunos testimonios, nos enteramos de que fue un poeta que gozó de cierto aprecio en su tiempo.

Esta edición de 1505, hecha en Roma, incluye, además de Annularia, la otra comedia de Egidio Gallo: Bophilaria. Ellas guardan importantes diferencias entre sí. Bophilaria, por de pronto, tiene solo 695 versos, en tanto que Annularia, 1225. Esta dispar extensión está en directa relación con el distinto grado de desarrollo de la acción dramática de una y otra pieza: mientras el argumento de Bophilaria es bastante sencillo, el de Annularia tiene bastante complejidad. 
de acceder expeditamente y en una edición saneada a esta desatendida pieza del humanismo latino ${ }^{3}$.

El influjo de la antigua comedia romana que las comedias humanísticas latinas dejan ver -en particular de Plauto- se aprecia, entre otros aspectos, en el vocabulario, los giros, las sentencias, la métrica y el empleo de recursos técnicos como la acotación, el aparte y el monólogo, en los que los autores exhiben, en general, un manejo bastante diestro. Esta influencia, sin embargo, no es homogénea a lo largo del Quattrocento. Como acabamos de señalar, la imitación de Plauto y Terencio es relativamente superficial en las primeras de estas piezas, testimoniando un conocimiento todavía incompleto de sus modelos. Posteriormente, sin embargo, al irse acrecentando la difusión y el estudio de la antigua comedia romana, su influencia se hace progresivamente más evidente. Es determinante, en este sentido, el hecho de que en 1476, en Florencia, se haya representado modernamente por primera vez a Plauto. A partir de ese momento, se produjo una seguidilla de representaciones de este autor y de Terencio en diversas ciudades de Italia, entre ellas Roma, donde vivía Egidio Gallo. Por primera vez entonces, desde la Antigüedad tardía, las comedias de Plauto y Terencio volvían a ser comprendidas como obras teatrales y no como textos destinados solo para la lectura.

Es así como, por ejemplo, ya el latín de Chrysis, de Enea Silvio Piccolomini, escrita a mediados del Quattrocento, es fraseológicamente bastante cercano al del teatro romano antiguo, del que con mucha fidelidad retoma palabras, giros y frases. La cuidadosa edición crítica que de esta obra hizo Enzo Cecchini recoge, en un segundo aparato, más de un centenar de loci similes de la antigua comedia latina, mayoritariamente plautinos, que testimonian esa estrecha dependencia.

Nuestro propósito en este trabajo es comunicar los resultados de una investigación que -en el marco de nuestro proyecto y en la misma línea de la que Cecchini realizó de Chrysis- hicimos de Annularia. El objetivo específico de ella fue determinar en detalle la influencia léxica y fraseológica que las comedias de Plauto ejercieron sobre esta comedia de Egidio Gallo, asunto

3 Agradecemos a la Biblioteca Universitaria de Bolonia, a la Biblioteca Nacional de París y al Museo Británico de Londres, depositarios de sendos ejemplares de la edición de Annularia de 1505 -los únicos supérstites, según nuestra información. Ellos tuvieron la gentileza de enviarnos microfilms de estos ejemplares, sin los cuales esta investigación no habría sido posible. 
que hasta aquí nadie había abordado ${ }^{4}$. Anticipando en parte los resultados, quisiéramos señalar que esta investigación, desde un mismo comienzo, nos puso frente a un hecho literario imprevisto y lleno de implicancias. Annularia, en efecto, desde sus versos iniciales, mostró un uso inesperadamente intensivo del procedimiento propio del centón, a saber, del recurso de construir una obra con fragmentos tomados de otras. Annularia, así, resultó ser, en buena medida, literatura prefabricada.

En los 1225 versos de Annularia descubrimos alrededor de 400 pasajes de origen plautino. De estos 400 pasajes, en este trabajo -para no extender excesivamente el registro- hemos seleccionado $104^{5}$. En general, los pasajes seleccionados han debido cumplir básicamente con dos requisitos: de un lado, que la intertextualidad sea muy nítida, y del otro, que la relación entre el pasaje de Annularia y el pasaje de Plauto sea biunívoca.

Es muy probable que existan más casos que esos aproximadamente 400 que nuestra pesquisa descubrió, por exhaustiva que haya procurado ser. A pesar de la inestimable ayuda que para una averiguación de este tipo presta hoy la informática -gracias a la cual, por ejemplo, es posible rastrear en segundos una determinada palabra o un determinado giro en el extenso corpus de las comedias de Plauto-, es muy posible que hayamos pasado por alto algunos casos por no haber sabido enderezar nuestra búsqueda en una determinada dirección.

En esta selección, por último, los pasajes de Annularia van dispuestos en la columna izquierda, ordenados de acuerdo al verso a que pertenecen, y van acompañados, en la columna derecha, de sus correspondientes fuentes plautinas.

4 Un trabajo similar hicimos con Bophilaria, la otra comedia de Egidio Gallo, cuyos resultados quedaron recogidos en el artículo "Las fuentes literarias de la comedia humanística latina Bophilaria, de Egidio Gallo".

En nuestra edición de Annularia se examinarán, en notas al texto latino, todos estos pasajes. Es importante señalar aquí, en todo caso, que frente a esos casi 400 pasajes de origen plautino, Annularia trae apenas 38 tomados de otros autores: Virgilio, Adriano, Valerio Flaco, Ovidio, Cicerón y, principalmente, Terencio. Esta proporción tan desigual de las fuentes, entre las que Plauto es abrumadoramente preferido, permite afirmar que Annularia es, en buena medida, un centón plautino. 


\section{COTEJO}

ANNULARIA

in platea ultima (verso 16)

(al fondo de la plaza)

hoc negat ille ultimus (30)

(ese que está al fondo dice que no)

dato pignus [...] Nihil agis? (47-8)

(haz una apuesta... ¿No haces nada?)

sedendo lumbi doleant (56)

([si hay alguien a quien le] duelan los riñones de estar sentado)

qui in hisce habitat cedibus (90)

(el cual vive en esta casa)

non mihi licere meam rem hic ut uolo loqui et agere / sine te arbitro? (120-1) (¿que no me sea posible hacer aquí mis cosas y hablar de ellas como se me antoje sin que tú estés de espía?)

miror ecastor te [...] tui officii non esse memorem (123-4)

(me sorprende, por Cástor, que no sepas cuál es tu deber)

istuccine serui frugi officium / esse autumas? (125-6)

(¿crees que este es el deber de un buen esclavo?)

hoccine pacto rem suam curari quum / rus abiret mandauit senex? (126-7)

(¿acaso el viejo ordenó que de este modo se velara por sus bienes cuando se fuera al campo?)

ut dies ac noctes hic bibas? Pergraceris? (127-8)

(¿que pases aquí los días y las noches bebiendo?, ¿que vivas a la griega?)
FUENTE

in platea ultima (Cur. 278)

negat hercle ille ultimus (Capt. 11)

pignus [...] dato.Nil agitis? (Cas. 75-8)

lumbi sedendo [...] dolent (Men. 882)

qui in hisce habitat aedibus (Trin. 12)

non mihi licere meam rem me solum ut uolo / loqui atque cogitare sine ted arbitro? (Cas. 89-90)

mirum ecastor te [...] officium tuom / non meminisse (Cas. 259-60)

hocine boni esse officium serui existumas [...]? (Mos. 27)

haecine mandauit tibi, quom peregre hinc it, senex? / Hocine modo hic rem curatam offendet suam? (Mos. 25-6)

dies noctesque bibite, pergraecamini (Mos. 22) 
age, [...] disperde rem (128)

(¡vamos, derrocha la hacienda!)

si curaret / quod suum est, itidem me curare sineret ancillas, qua mea est curatio (129-30)

(si se ocupara de lo que es suyo, dejaría también que yo me encargara de las esclavas, que es mi ocupación)

malum / quod tibi dii dent, atque ego dabo (131-2)

(que los dioses te castiguen por esto, como yo también lo voy a hacer)

heus uos, ecquis hoec quo loquor audit? (135)

(¡eh, ustedes!, ¿hay, por ventura, alguien que oiga lo que estoy diciendo?)

si Ioui sacruficem (137)

(si le hago sacrificios a Júpiter)

quasi mus in medio pariete (140)

(como un ratón al interior de una pared)

quid sic alte petiisti suspirium? (147)

(¿por qué has lanzado un suspiro tan profundo?)

conditum erat in pectore ponitissimo (148) abscondas pectore penitissimo (Cist. 63)

(estaba escondido en lo más íntimo del pecho)

pudicitiam meam imminuit mihi (176) pudicitiam imminuit meam mihi (Cist. 88)

(me quitó la inocencia)

is me clanculum / usque ad fores consequitur (180-1)

(él me sigue a escondidas hasta la puerta)

quid uerbis opus est? / Occipio illum amare (181-2)

(¿para qué decir más? Me enamoro de él)

ut mihi exciuisti lachrymas! (187)

(¡cómo me has hecho derramar lágrimas!) age [...] disperde rem (Cas. 249)

si facias recte aut commode, / me sinas curare ancillas, quae meast curatio (Cas. 260-1)

malum quod tibi di dabunt, atque ego hodie / dabo (Am. 563-4)

heus uos, ecquis haec quae loquor audit? (Cas. 165)

si sacruficem summo Ioui (Ps. 265)

quasi mus in medio pariete (Cas. 140)

uide ut petiuit / suspiritum alte (Cist. 55-6)

consecutust clanculum me usque ad fores (Cist. 91)

quid opust uerbis? [...] / Coepi amare [...] ego illum (Cist. 94-5)

ut mihi exciuisti lacrimas! (Cist. 112) 
cupio illum mihi dari / ut uorsem (189-90) (estoy deseosa de que me lo pongan delante para manipularlo)

sed hoc factum est; quin factum sit fieri non potest (202)

(pero esto sucedió, y no puede hacerse que no haya sucedido) ad malum accedit malum (204) (a una desgracia se añade otra) uerum auis captiua, et si captiua sit, et si fugce nulla pateat / potestas, tamen animo libera est; nam si semel fugam dederis, / facta est auctio: nunquam post prehendas (205-7)

(pero un ave cautiva, aunque esté cautiva, aunque ninguna posibilidad de huida se le presente, sin embargo es libre de espíritu. Prueba de ello es que, si tan solo una vez le das la oportunidad de huir, la venta está hecha: nunca después la podrías capturar)

fluxam fidem / geram (214-5)

([de nada sirve] que guarde una fidelidad vacilante)

procurem sedulo quod in rem conducat suam / id potissimum corde cupere et animo atque eniti uiribus (215-6)

([de nada sirve] que procure celosamente, sobre todo, desear con mi corazón y mi espíritu lo que convenga a sus intereses y en ello me afane con todas mis fuerzas) neque [...] ingenio fuisse discordabili (217)

(y [de nada sirve] que nunca haya estado en desacuerdo)

neque illi me unquam aduorsatum ac morem / gessisse (218-9)

(y no me haya opuesto alguna vez a él, sino que lo haya complacido a su gusto) mihi istunc uellem hominem dari; / ut ego illum uorsarem! (Cist. 93-4)

factum est illud; fieri infectum non potest (Aul. 741)

ad malum accedit malum (Men. 82)

liber captiuus auis ferae consimilis est: / semel fugiendi si data est occasio, / satis est, numquam postilla possis prendere (Capt. 116-8)

fidem fluxam geras (Capt. 439)

faciam sedulo / ut potissimum quod in rem recte conducat tuam, / id petam id persequarque corde et animo atque uiribus (Capt. 385-7)

fuisse ingenio haud discordabili (Capt. 402)

neque me aduersatum tibi / beneque ero gessisse morem (Capt. 403-4) 
et mea opera et comitate et fide / et sapientia (223-4)

(con mi actuación, mi bondad, mi fidelidad y mi prudencia) nunquam tamen erit tam gratus ut / me mittat тапи (224-5)

(nunca, sin embargo, estará tan agradecido como para manumitirme)

ego sum herus, idem egomet mihi / sum seruus (250-1)

(yo soy mi amo, y también yo mismo soy mi esclavo)

amicis publice operam dant (271)

(prestan servicios a sus amigos en lugares públicos)

bene uiuitur et fortunate, / et ut quisque uult atque ut cuique animo lubet (278-9) (se vive bien y acomodadamente, como uno quiere y le da la gana)

solum hoc oneris me macerat, quod fero / annos sexaginta. Accedit [...] (285-6) (la única carga que me mortifica es que sobrellevo sesenta años. Se agrega [...]) in cedes intromiserim oblatratricem (287-8)

([se agrega la desgracia de] que yo haya introducido en mi morada una perra ladradora)

simulabo quasi / non uiderim (293-4) (haré como que no lo he visto)

arbitramini / uobis licere ac lubere rem perdere? Dies ac noctes bibere? (301-2) (¿creen que ustedes pueden derrochar la hacienda como se les antoje?, ¿beber durante días y noches?)

uola curriculo (303)

uola curriculo (Per. 199)

et mea opera [...] et comitate et uirtute et sapientia (Capt. 409-10)

numquam erit tam auarus, quin te gratiis [var. lect.: gratus] emittat manu (Capt. 408)

egomet sum mihi imperator, idem egomet mihi oboedio (Mer. 853)

in foro operam amicis da (Trin. 651)

bene uino et fortunate atque ut uolo atque animo ut lubet (Mil. 706)

tantum hoc onerist quod fero [...] annos octoginta et quattuor; [...] accedit [...] (Merc. 672-4)

oblatratricem in aedis intro mittere (Mil. 681)

simulabo quasi non uideam (Per. 84)

dum tibi lubet licetque, [...] perde rem; / [...] dies noctesque bibite (Mos. 20-2)

(vete volando [liter. vuela en tu carrera]) 
istuc scire expeto (304)

(tengo muchas ganas de saberlo)

urbanos solere fieri rusticos (307)

([dile] que los de la ciudad suelen adoptar

los modales de los del campo)

uxorem usurariam (309)

(una esposa prestada)

uerbereum caput (310)

(carne para el látigo)

ille cedepol / te mortuam extra domum uidere, credo ecastor, uellet (312-3)

(él, por Pólux, quisiera verte muerta fuera de la casa, creo, por Cástor)

at ego pol non credo, sed certa res est (315) (no es que yo lo crea, por Pólux, sino que estoy segura)

ociosum arbitror / te esse; aliena curas (326-7)

(tú debes ser alguien que no tiene nada que hacer, pues te andas ocupando de asuntos ajenos)

sed tristis egreditur; blande appellanda est (341)

(pero viene saliendo enojada; tendré que hablarle con dulzura)

cana culex (343)

(mosca canosa)

manifesto teneris, miser (343)

(has sido sorprendido con las manos en la masa, desdichado)

scio plusquam rere (345)

(sé más de lo que tú crees)

quid nam id est? (346)

(¿y qué es esto?) istuc expeto scire (Cas. 185 y 669)

urbani fiunt rustici (Mer. 714)

uxorem [...] usurariam (Am. argum. I, 3)

uerbereum caput (Per. 184)

CHAL. Ille (uult) edepol uidere ardentem te extra portam mortuam. / CLEO. Credo ecastor uelle (Cas. 354-5)

at pol ego hau credo, sed certo scio (Cas. 355)

otiosum te arbitror hominem esse. / [...] alienis rebus curas (Truc. 136-7)

tristem astare aspicio; blande haec mihi mala res appellandast (Cas. 228)

cana culex (Cas. 239)

manufesto, miser, teneor (Cas. 237)

scio plus quam tu me arbitrare (Cas. 243)

quid id est (Cas. 243) 
te sene omnium / qui uiuant nemo est senex nequior (346-7)

([sé] que, de entre todos los que existen, no hay viejo más desvergonzado que tú) senecta cetate (350)

(en la vejez)

pol ego cuidam amico hodie operam [...] (367)

(por Pólux, hoy [le prometí] mi ayuda a un amigo)

domuistin animum?(369)

(¿has dominado tu carácter?)

bellam [...] tenellam (392)

(bella, tiernecita)

mecum coniecturam facio (448)

(me formulo interiormente una conjetura)

illum pugnis / onerabo (456-7)

(lo voy a cubrir de golpes)

pro aggerunda curuum aqua faciam (457)

([lo] dejaré encorvado como para cargar agua)

quam tibi mandaui rem meam / inopiosam consilii $[\ldots](462-3)$

(el encargo que te hice, que requería de tu ingenio)

sapienter, cordate et cate (468)

(sabia, cuerda y astutamente)

grates gratias (471)

(muchísimas gracias)

nequaquam obsecras (472)

(ruegas en vano)

corios bubulos [...] ut in tergo conterantur тео (474-5)

([traigan] los látigos de cuero para gastarlos en mi espalda) te sene omnium senem neminem esse ignauiorem (Cas. 244)

senecta aetate (Cas. 240)

pol ego amico dedi quoidam operam (Cas. 241)

domuisti animum (Cas. 252)

bellam et tenellam (Cas. 108)

coniecturam [...] mecum facio (Rud. 771)

onerandus est pugnis (Am. 328)

aggerunda curuom aqua faciam (Cas. 124)

ego res multas tibi mandaui [...] inopiosas consilii (Poen. 129-30)

sapienter [...] cordate et cate (Poen. 131) grates gratias (Poen. 134)

nequiquam hercle obsecras (Mil. 1396)

in tergo meo / [...] corios contriuisti bubulos (Poen. 138-9) 
si per amorem malefeci tibi, id mihi / amanti ignoscito (478-9)

(si por culpa de un amor te he perjudicado, perdóname: estoy enamorado)

nunc blandidicus es (489)

(ahora estás cariñoso)

res meas reddidisti opiparas opera tua (497)

(has vuelto abundantes mis bienes con tu intervención)

ex tristi fecisti lenem (500)

(de arisco [me] hiciste apacible)

si quid bono / boni feceris, numquam perit (519-20)

(si le haces un bien a un hombre bueno, [eso] nunca queda sin recompensa)

te [...] cum sorore (matre ante corr.) sua insinuasse muneribus (526)

([dices] que te congraciaste con su hermana mediante regalos)

Orcum scire oportet (556)

(el Orco debe saber)

Venus uenusta, oro atque obsecro ut quem expeto, ut quem amo, is mihi tuo numine benignus siet (570-1)

(hermosa Venus, te ruego y suplico que consientas en que aquel a quien deseo y amo me sea favorable)

adsum, quem tu uadaris Venereis / uadimoniis (577-8)

(aquí estoy yo, a quien tú has enviado una citación de amor)

uno / in saltu tres cepisse apros (593-4) ([diré] que en un solo bosque cacé tres jabalíes) per amorem si quid feci [...] mihi amanti ignoscito (Poen. 140-4)

nunc mihi blandidicus es (Poen. 138)

quas (res) [...] mihi reddidisti opiparas opera tua (Poen. 131-2)

faciet ex tristi [...] lenem (Cas. 223)

bonis quod bene fit haud perit (Rud. 939)

insinuauit cum matre [...] muneribus (Cist. 92-3)

Orcum scire oportet (Capt. 283)

Veneri pol habeo gratiam eandemque et oro et quaeso / ut [...] quem amo quemque expetesso / benignus erga me siet (Mil. 1228-30)

ubi tu es, qui me conuadatu's Veneriis uadimoniis? (Cur. 162)

uno in saltu [...] apros capiam duos (Cas. 476) 
dii boni, quot blanditias, quot saltationes, / quot uoluptates feram! (600-1)

(¡dioses buenos, cuántas caricias, cuántos bailes, cuántos placeres experimentaré!) quot ego te hodie miserum male / habebo modis! (628-9)

(¡de cuántos modos te voy a hacer desdichado hoy!)

Iuppiter te perdat, ita oboluisti allium (634)

(que Júpiter te pierda, como es cierto que hueles a ajo)

ut atrior sis quam Agyptii (638)

([te voy a golpear a tal punto] que terminarás más negro que los egipcios) acerrimus, legirupa, parricida, / qui patrem atque matrem occidisti (673-4) (cruelísimo, quebrantador de la ley, parricida, que mataste a tu padre y a tu madre)

quid clamoris audiui modo in via ante cedis meas? (679)

(¿qué grito es el que acabo de oír en la calle frente a mi casa?)

quid tibi hunc tactio fuit? (690)

(¿por qué tuviste que ponerle la mano encima?)

feri $[. .$.$] ut ille rursus (691)$

(golpéalo de vuelta tal como él [te golpeó])

principium non placet (709)

(el comienzo no me agrada)

quem qui sit homo nescio / neque noui (769-70)

(quien no sé quién es y al que no conozco)

huic lassitudo medullam perbiberat (771) cui medullam lassitudo perbibit (St. 340)

(la fatiga lo había calado hasta los tuétanos) pro di immortales, quot ego uoluptates fero, / [...] / saltationes, blanditias (St. 657-9)

quot te modis / [...] habebo [...] miserum (Cas. 115-6)

te Iuppiter / dique omnes perdant, $f u$, oboluisti alium (Mos. 38-9)

atrior [...] ut siet / quam Aegyptini (Poen. 1290-1)

PSEVD. Parricida. [...] CAL. Legirupa. [...] BAL. Acerrume. [...] CAL. Verberauisti patrem atque matrem. BAL. Atque occidi quoque [...] (Ps. 362-7) meas? (Trin. 1093)

quid tibi tactio hunc fuit (Cas. 408)

feri [...] ut ille rursum (Cas. 407)

non placet principium (Am. 801)

quem ego qui sit homo nescio / neque noui (Trin. 849-50) quid hoc hic clamoris audio ante aedis 
ad se ad conam uocet. Relligio mihi uocat me ad cenam; religio fuit (Cur. 350) fuit (778)

([pide que alguno de nosotros lo] invite a cenar a su casa. Yo lo consideré un deber)

postquam conati atque appoti (779) postquam cenati atque appoti (Cur. 354)

(después de que comimos y bebimos en abundancia)

ille caput deponit. Ego ubi hominem uidi caput deponit, condormiscit. Ego ei edormiscere, subduco illi annulum (780-1) subduco anulum (Cur. 360)

(él inclina la cabeza. En cuanto vi que el tipo se quedaba dormido, le sustraje el anillo)

quid ille se/in senatum seuocat? (850-1) quid tu te solus e senatu seuocas? (Aul. (¿por qué él se retira a deliberar solo?) 549)

Abi igitur. / Tu me nemini indicabis, ego abi [...] / nec tu me cuiquam indicassis mussitabo furtum tuum (863-4)

(por lo tanto, vete. Tú no me vas a acusar ante nadie, y yo voy a mantener en secreto tu robo)

iam ego tibi obstringam collum, abducam in malam crucem (869) [...]; / tu taceto, ego mussitabo (Rud. $1027-9)$

collum obstringe, abduce istum in malam crucem (Cur. 693)

(ahora te pondré una soga al cuello y te llevaré al patíbulo)

dii boni, nam quis alter est / cui dii magis sint propitii quam mihi? Quibus me donarunt hodie / gaudiis! (874-6) (dioses buenos, ¿qué otro hay a quien los dioses sean más propicios que a mí? ¿Qué alegrías me han dado hoy!)

trecentce sunt / causce (912-3)

trecentae possunt causae conligi (Mil. 250)

(hay trescientas excusas [que puedes alegar])

cui dii / sunt propitii, semper illi aliquid obiiciunt boni (919-20)

di immortales, quibus et quantis me donatis gaudiis! [...] Quis me Athenis nunc magis quisquam est homo cui di sint propitii? (Aul. 808-10)

(a quien los dioses son propicios, a ese siempre le ponen delante algo bueno) maledicis maiori, uenefice? (928) uenefice, [...] male dicis maiori (Per. (¿te atreves a insultar a alguien mayor 278-80) que tú, tramposo?) 
propinabo tibi cantharum uini ueteris cadum tibi ueteris uini propino (St. 425$)$

(933)

(te regalaré una jarra de vino añejo)

flore libyco (999)

(vino egipcio)

iubet os prcecidi mihi (1024)

flore libyco (Cas. 640)

([ella le] ordena que me rompa la cara)

tene marsupium; obsona ampliter (1031) tene marsuppium; / abi atque obsona

(toma la bolsa; compra en abundancia) [...]; obsonato ampliter (Cas. 490-501)

qui nati sunt bono / genere (1076-7) qui bono sunt genere nati (Mer. 969)

(quienes han nacido de buen linaje)

tu mihi es pater, uerum nihilosecius tu mihi nihilo magis unicus est ille mihi filius pater es quam ego tibi / gnata (1109-10) quam ego illi pater (Cas. 264)

(tú eres mi padre, pero tal como tú eres mi padre, yo soy tu hija)

obsecro ne meos mihi parentes auferas

obsecro parentes ne meos mihi prohibeas (Cur. 605)

(te ruego que no me quites a mis padres)

PHI. Ecquid / meministi nomen patris? Dv. Memini (1200-1)

(FILADELFIs. ¿Por ventura recuerdas el

-Ecquid meministi tuom parentum nomina, / patris atque matris? -Memini nombre de tu padre? Duléutero. Lo recuerdo)

\section{CONCLUSIONES}

El cotejo de Annularia con el teatro de Plauto permite apreciar muy bien la envergadura de la influencia léxico-fraseológica que las comedias de Plauto ejercieron en Annularia. Sobre el particular, sin embargo, es conveniente hacer algunas observaciones que precisan el alcance de los datos expuestos.

Un primer asunto digno de señalar es el que dice relación con el Plauto que Egidio Gallo manejó. Sabemos que durante la Edad Media y hasta iniciado el Humanismo se conocieron solamente 8 comedias de Plauto: Amphitruo, Asinaria, Aulularia, Captiui, Casina, Cistellaria, Curculio y Epidicus. Este fue el Plauto que tuvieron a su disposición los primeros autores de comedias humanísticas latinas. El códice con las 12 comedias restantes fue descubierto recién en 1429 por Nicolás de Cusa y tardó tiempo en difundirse 
en los círculos humanistas. Todavía en 1441, Lorenzo Valla, en carta del 18 de marzo a Giovanni Tortelli, expresa el deseo de tener en sus manos una copia de estas piezas "recientemente descubiertas" (recenter invente), con el fin de enriquecer la documentación de sus Elegantiae linguae Latinae, por entonces en proceso de redacción (Valla 210).

Pues bien, hecha esta precisión, corresponde señalar que Egidio Gallo manejó la totalidad del corpus plautino. Aunque -en la muestra que hemos presentado, aleatoria en este aspecto- una leve mayoría de los pasajes de Plauto retomados en Annularia es de alguna de esas ocho comedias conocidas en la Edad Media(58\%), un número importante de ellos pertenece a alguna de las otras, a las recenter invente que menciona Valla (42\%). A pesar de lo parcial de nuestra muestra -que, como quedó dicho, recoge 104 de los aproximadamente 400 pasajes de origen plautino-, en ella encontramos citas de 10 de las otras 12 comedias: Menaechmi, Mercator, Miles Gloriosus, Mostellaria, Persa, Poenulus, Pseudolus, Rudens, Stichus, Trinummus y Truculentus.

Un segundo hecho que conviene señalar para la debida comprensión del cotejo es que el carácter de los casos de intertextualidad que aquí hemos consignado no es siempre el mismo. A veces, en efecto, la condición de fuente de un preciso pasaje de Plauto es segura. Esto es así, por ejemplo, cuando en Annularia encontramos un hápax plautino, como en uerbereum caput (310), que recoge el uerbereum caput de Persa 184, pasaje que contiene la única documentación anterior a la de Annularia de la voz uerbereus, o bien en el caso de quam tibi mandaui rem meam / inopiosam consilii [...] (462-3), que registra la única documentación de inopiosus -adjetivo "humorously formed after copiosus" (OLD)- aparte de la de Poenulus 130. También hay certeza del origen plautino de un pasaje de Annularia cuando en esta y en Plauto encontramos una misma frase o un mismo giro de cierta extensión. Tales pasajes, como es natural, de ninguna manera pueden haberse generado independientemente. Otras veces, en cambio, más que una influencia directa de un pasaje de Plauto, lo que hay es la influencia de un pasaje de Plauto que encontramos en dos o más lugares de sus comedias ${ }^{6}$. Y en otras ocasiones, en fin, se trata de un pasaje que se encuentra también en otros autores de la antigua latinidad. En estos casos, lo importante para nosotros es que ese pasaje también se encuentra en Plauto. 
Para establecer que un determinado pasaje de Plauto es fuente de alguno de Annularia no hemos considerado necesario que exista una completa igualdad entre ellos, naturalmente. Hay una serie de casos en los cuales, a pesar de que el pasaje de Plauto ha sido intervenido por Egidio Gallo, no cabe duda de su condición de fuente de un pasaje de Annularia. Un caso con modificaciones leves es, por ejemplo, istuccine serui frugi officium / esse autumas? (125-6), que retoma el pasaje plautino hocine boni esse officium serui existumas [...]? (Mos. 27). Aquí la variación introducida por Egidio Gallo estriba en la sustitución de dos palabras por sinónimos (frugi/boni y autumas/existumas). Algo mayor es la intervención cuando se funden dos oraciones en una, como ocurre en hoccine pacto rem suam curari quum / rus abiret mandauit senex? (126-7), modelado sobre el pasaje plautino Haecine mandauit tibi, quom peregre hinc it, senex? / Hocine modo hic rem curatam offendet suam? (Mos. 25-6). A veces lo que hay es una modificación de categorías gramaticales, como entre Vt dies ac noctes hic bibas? Pergrceceris? (127-8) y Dies noctesque bibite, pergraecamini (Mos. 22), donde además hay cambio de tipo de oración (de imperativa a interrogativa). Una modificación algo mayor se da cuando se refunden dos parlamentos en uno, como en el caso de ille cedepol / te mortuam extra domum uidere, credo ecastor, uellet (312-3), que reformula el pasaje plautino CHAL. Ille (uult) edepol videre ardentem te extra portam mortuam. /CLEO. Credo ecastor uelle (Cas. 3545), o cuando se condensan varios parlamentos en uno, como en acerrimus, legirupa, parricida, / qui patrem atque matrem occidisti (673-4), que recoge segmentos de cinco parlamentos plautinos sucesivos: PSEVD. Parricida. [...] CAL. Legirupa. [...] BAL. Acerrume. [...] CAL. Verberauisti patrem atque matrem. BAL. Atque occidi quoque [...] (Ps. 362-7).

De mucho interés es agregar aquí que algunos pasajes de Annularia que presentaban alguna dificultad (textual, de sentido, sintáctica, etc.) fueron cabalmente aclarados en el momento mismo en que logramos identificar su fuente. Por ejemplo, los versos uerum auis captiua, et si captiua sit, et si fugce nulla pateat / potestas, tamen animo libera est; nam si semel fugam dederis, / facta est auctio: nunquam post prehendas (205-7) retoman el pasaje plautino liber captiuus auis ferae consimilis est: / semel fugiendi si data est occasio, / satis est, numquam postilla possis prendere ${ }^{7}$ (Capt. 116-8), y

\footnotetext{
"Un hombre libre hecho cautivo es semejante a un ave salvaje: si se le da una sola vez la ocasión de huir, es suficiente; nunca después puedes atraparla".
} 
solamente gracias a estos versos de Captiui nos fue posible estar seguros del sentido del segmento facta est auctio (cuyo significado literal era claro: 'la venta está hecha') de Annularia, que aquí debe entenderse como un refrán, con el significado de 'ya no hay nada que hacer', 'ya no hay vuelta atrás'.

Para representarse, así sea parcialmente, el modo de trabajo de Egidio Gallo al componer su pasticcio, puede ser iluminador observar lo que ocurre en los versos 214 y siguientes de Annularia, recogidos en nuestra selección. La escena tercera del acto segundo de Captiui (vv. 361-460), en la que participan esclavos fieles y de nobles sentimientos, le proporciona a Egidio Gallo importante "materia prima" para elaborar esta escena de Annularia, en particular el parlamento del esclavo Duléutero. Lo mismo podría señalarse a propósito del pasaje sed tristis egreditur; blande appellanda est (341) y los citados a continuación de él, que recogen una serie de fragmentos vecinos de Casina, o bien de los pasajes quam tibi mandaui rem meam / inopiosam consilii [...] (462-3) y siguientes, que retoman pasajes vecinos de Poenulus. En todos estos casos hay una suerte de enjambre de pasajes plautinos, contiguos y relacionados, que Egidio Gallo trasplanta a su Annularia.

\section{CONSIDERACIONES FINALES}

El examen que hemos realizado permite hacerse una idea del modo de trabajo de algunos humanistas al momento de escribir sus obras y puede servir como punto de partida para otras aproximaciones al fenómeno de la creación durante los siglos del Renacimiento. Si bien nuestro trabajo aborda un ámbito definido de Annularia -las correspondencias léxico-fraseológicas con las comedias de Plauto-y no contempla su interpretación literaria, quisiéramos formular, para concluir, algunas breves consideraciones referentes al proceso de recuperación, recepción e imitación de la tradición clásica que se da en esta comedia.

La dependencia estrecha del modelo plautino en la comedia de Egidio Gallo refleja la intención de crear una obra enteramente al modo del autor clásico. El alto número de préstamos que presenta bien permite calificar de centonario -como se había anticipado- el procedimiento creativo y asociarlo a las corrientes más rigurosas de imitación de los modelos de la Antigüedad; no debe olvidarse, por cierto, que la comedia humanística surge precisamente como un verdadero ejercicio de imitación. 
No percibimos en Annularia, en cambio, un propósito manifiesto de obtener una obra capaz de competir o superar a su referente, a pesar de que coincide temporalmente con la llamada época de la "emulación" y de apogeo del Renacimiento (ca. 1490-1530) ${ }^{8}$. Sin embargo, resulta claro que, por mucho que un autor pretenda llevar a cabo una imitación estricta, el contexto de creación siempre va a condicionar la obra en algún grado. De este modo, nos encontramos en esta comedia, por ejemplo, con léxico propio de su momento de creación, así como también con personajes y motivos que responden más a la época de Gallo que a la de Plauto: tal es el caso de la joven Pasicompsa y sus palabras llenas de carácter, personaje impensable en la antigua comedia latina. Resulta pertinente, entonces, aludir a la llamada "recepción creativa" y a la propuesta de un "filtro" existente entre el modelo y la nueva obra".

La postura artística de Annularia, por cierto, no es la de nuestra época. Los centones nos parecen hoy, más bien, una habilidosa técnica de montaje. Pero no debemos equivocarnos: en descargo del centón hay que decir que el descrédito contemporáneo de este tipo de composiciones implica una concepción de la originalidad y del poeta creador que era extraña a la antigüedad. Para el escritor antiguo, depender de otro era un título de honra. Lo grave era no tener el respaldo de una autoridad. Para nosotros, en cambio -posrománticos, al fin-,todo buen escrito debe ser enteramente original.

Comoquiera que sean las cosas, en fin, resulta admirable confirmar en Annularia la devoción con que los humanistas del Quattrocento se dejaron fecundar por la riqueza de la tradición literaria grecolatina.

8 Cf. Burke, "La era de la emulación: el apogeo del Renacimiento", en El renacimiento europeo, pp. 64-91. En la introducción de su libro, Burke identifica tres fases en la recepción renacentista de la Antigüedad: "La historia comienza con el redescubrimiento de la cultura clásica y los primeros intentos de imitación. Luego viene la fase de la maestría, el llamado apogeo del Renacimiento, en el que las reglas para la combinación de diferentes elementos han sido aprendidas y la imitación se vuelve emulación. La tercera y última fase es la de una deliberada transformación, de una ruptura con las reglas" (22).

9 Muy interesante resulta el hecho de que Peter Burke se refiera no a uno, sino a varios filtros en el caso del Renacimiento: "Una de las ideas o metáforas centrales en los estudios modernos de la recepción es la imagen de 'retícula' o 'filtro', que permite que algo pase pero no todo. Lo que se selecciona debe ser 'congruente' con la cultura donde la selección se opera. En el caso del Renacimiento, necesitamos primero ser conscientes del antiguo filtro romano, puesto que los romanos no sólo adoptaron la cultura griega, sino que la adoptaron a sus propias necesidades. En segundo lugar, existieron los filtros bizantino y árabe, a través de los que la antigua cultura griega fue recibida en la Edad Media. En tercer lugar, está presente el filtro medieval. [...] En cuarto lugar, tenemos el filtro italiano [...]" (17). 


\section{BIBLIOGRAFÍA}

Arbea, Antonio. "Las fuentes literarias de la comedia humanística latina Bophilaria, de Egidio Gallo”. Onomázein 18 (2008): 153-171.

Burke, Peter. El Renacimiento europeo. Centros y periferias. Barcelona: Crítica, 2000.

Gallo, Egidio. Comoediae. Roma: J. de Besicken, 1505.

Oxford Latin Dictionary (OLD). Ed. P. G. W. Glare. Oxford: Clarendon Press, 1982.

Piccolomini, Enea Silvio. Chrysis. $1444^{10}$. Ed. Enzo Cecchini. Firenze: Sansoni Editore, 1968. Plauto, T. Maccio. Comoediae. 1904. Ed. W. M. Lindsay. Oxford: Clarendon Press, 1963.

Valla, Lorenzo. Epistole. $1441^{11}$. Eds. Ottavio Besomi y Mariangela Regoliosi. Padova: Editrice Antenore, 1984. 